\title{
Lack of effect of relaxin on oxytocin output from the porcine neural lobe in vitro or in lactating sows in vivo
}

\author{
D. G. Porter, P. L. Ryan and L. Norman \\ Department of Biomedical Sciences, Ontario Veterinary College, University of Guelph, Guelph, \\ Ontario, Canada NIG 2WI
}

\begin{abstract}
Summary. Oxytocin was measured in incubates and perifusates of neurosecretosomes prepared from sow neural lobes $(n=50)$ and in incubates of isolated neural lobes $(n=$ 5). In none of these preparations was oxytocin output affected by exposure to purified porcine relaxin (at concentrations up to $10^{-7} \mathrm{~mol}^{-1}$ ). Moreover, in lactating sows $(n=9), 6-10$ days post partum, the administration of porcine relaxin ( 1.5 or $3.0 \mathrm{mg})$ intravenously, immediately before a suckling episode, did not affect the plasma oxytocin profile compared with saline treatments (within sow) nor did it alter suckling behaviour or the weight gain of the litter. In all sows, a spike $\left(25-75 \mathrm{pg} \mathrm{ml}^{-1}\right)$ of oxytocin was measured during milk ejection coincident with suckling. These results suggest that porcine relaxin does not affect oxytocin release in suckling sows in contrast to reported findings in rats. The data also support the view that porcine relaxin could be used at farrowing without adverse effects on suckling.
\end{abstract}

Key'words: oxytocin; relaxin; suckling; neural lobe; pig

\section{Introduction}

The demonstration that relaxin suppresses reflex milk ejection (Summerlee et al., 1984) and inhibits oxytocin release from the neural lobe in lactating rats (O'Byrne et al., 1986) has been confirmed in parturient rats (Jones \& Summerlee, 1986a). Relaxin has been shown to affect oxytocin release from the rat neural lobe in vitro (Dayanithi et al., 1987). In heifers in late pregnancy it is claimed that administration of porcine relaxin stimulates oxytocin release (Musah et al., 1989). There have been no reports in other species. A positive association between plasma titres of relaxin, measured during the interval between the pre partum surge of relaxin concentrations (Sherwood et al., 1981) and the onset of parturition, and the duration of farrowing (Wathes et al., 1989) is consistent with the idea that relaxin may inhibit oxytocin release in sows.

There are economic and animal welfare reasons for enquiring whether relaxin affects oxytocin output in species other than rats. In sows, the administration of relaxin could be used therapeutically to decrease the number of stillbirths, as the hormone has been shown to be essential for live delivery of the fetuses (Nara et al., 1982) and may improve myometrial coordination (Downing et al., 1980). However, if it interferes with oxytocin release its administration to parturient sows could be contraindicated because of effects on milk ejection.

We attempted to answer this question using in vitro methods but our failure to affect oxytocin release from neural lobes in vitro lead us to question whether our results were in vitro artefacts. We therefore studied the effects of administration of porcine relaxin in vivo on the oxytocin release that accompanies milk ejection in lactating sows. 


\section{Materials and Methods}

\section{In vitro studies}

Preparation of tissue. Pituitary glands were obtained from nonpregnant sows (Yorkshire crossbreds) in various but unknown stages of the oestrous cycle. The animals were supplied by the University Swine Research Centre following slaughter at the Meat Science Laboratory abattoir, Department of Animal and Poultry Science. The glands were transported to the laboratory in warm $\left(37^{\circ} \mathrm{C}\right)$ normal Lockes' solution (NLS) (containing $140 \mathrm{mmol} \mathrm{NaCl} 1^{-1}$, $5 \mathrm{mmol} \mathrm{KCl1} 1^{-1}, 5 \mathrm{mmol} \mathrm{NaHCO} \mathrm{I}^{-1}, 1 \mathrm{mmol} \mathrm{MgCl}_{2} \mathrm{I}^{-1}, 10 \mathrm{mmol}$ glucose $\mathrm{I}^{-1}, 10 \mathrm{mmol}$ Hepes $\mathrm{I}^{-1}, 0.01 \%$ bovine serum albumin (BSA) at $\mathrm{pH} 7 \cdot 2$ ). The neural lobe was separated from the rest of the pituitary gland and neurosecretosomes were prepared from it as described by Cazalis et al. (1987) with the following slight modifications.

Briefly, the lobes were minced with a sharp razor blade in $500 \mu$ of a sucrose solution $\left(270 \mathrm{mmol}^{-}\right.$sucrose $^{-1}$,

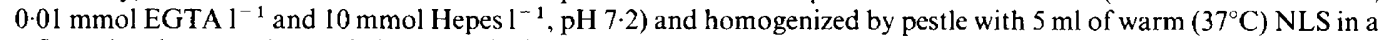
teflon-glass homogenizer at 950 r.p.m. The homogenate was then centrifuged in a prewarmed tube for $5 \mathrm{~min}$ at $300 \mathrm{~g}$ (Beckman centrifuge, model J2-21M), to remove cell debris. The supernatant was decanted and recentrifuged at room temperature for $15 \mathrm{~min}$ at $3400 \mathrm{~g}$. This supernatant was discarded and the pellet resuspended with $2.5 \mathrm{ml} \mathrm{NLS}$ at $37^{\circ} \mathrm{C}$ and centrifuged for a further $15 \mathrm{~min}$ at $3400 \mathrm{~g}$. The supernatant was again discarded and the neurosecretosome pellet was resuspended in $2.5 \mathrm{ml}$ warm choline chloride solution (containing $145 \mathrm{mmol}$ choline chloride $1^{-1} ; 5 \mathrm{mmol}$ $\mathrm{NaHCO}_{3} \mathrm{I}^{-1} ; 2 \cdot 2 \mathrm{mmol} \mathrm{CaCl} 1^{-1} ; 1 \mathrm{mmol} \mathrm{MgCl} \mathrm{l}^{-1} ; 10 \mathrm{mmol}$ glucose $1^{-1} ; 10 \mathrm{mmol}$ Hepes $1^{-1} ; 0.01 \%$ BSA at $\mathrm{pH}$ 7.2). The neurosecretosome suspensions used for perifusion were filtered with a coarse Millipore prefilter (Millipore Corp., Bedford, USA) to a final volume of $2.5 \mathrm{ml}$. A portion of each of two of the pellets was retained for electron microscopy.

Incubation studies. Aliquots, $50 \mu 1$, of neurosecretosome suspension were pipetted for incubation into $1.5 \mathrm{ml}$ Eppendorf tubes containing $950 \mu \mathrm{l}$ of either choline chloride or $\mathrm{KCl}$ (containing $125 \mathrm{mmol} \mathrm{KCl} \mathrm{I}^{-1}$ or $20 \mathrm{mmol}$

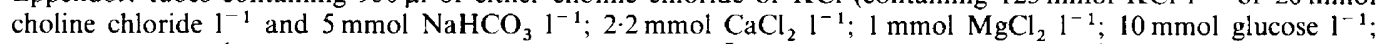
$10 \mathrm{mmol} \mathrm{Hepes} 1^{-1} ; 0 \cdot 01 \% \mathrm{BSA}, \mathrm{pH} 7 \cdot 2$ ) with or without $10^{-7}$ mol purified porcine relaxin $1^{-1}$. Each treatment group consisted of between eight and ten replicates. The tubes were then placed in a shaker water bath (Hotpack Shaker, Waterloo, Canada) and incubated at $37^{\circ} \mathrm{C}$ for $45-50 \mathrm{~min}$. After incubation the Eppendorf tubes were centrifuged for $15 \mathrm{~min}$ at 8000 r.p.m. in a microcentrifuge (Biofuge A, Hereaus Sepatech, Germany) and the supernatant was aspirated and stored in polypropylene vials at $-20^{\circ} \mathrm{C}$ until assayed for oxytocin content. The resultant pellet was also stored at $-20^{\circ} \mathrm{C}$ for protein determination. A set of samples from each treatment group that were not incubated were also stored at $-20^{\circ} \mathrm{C}$ to provide estimates of hormone content at time zero.

Perifusion studies. Perifusion studies were performed in $25 \mathrm{~mm}$ syringe filter units (Millex GV, Millipore Products) containing a $0.22 \mu \mathrm{m}$ filter. Tygon plastic tubing $(1.6 \mathrm{~mm}$, Type II, Fischer Scientific, Whitby, Canada) was attached to both ends of each of two perifusion chamber units, one leading from a solution reservoir (afferent tube) and the other leading to a fraction collector (efferent tube). Perifusion solutions were delivered through the afferent tube to individual chambers by means of a four-channel peristaltic pump (Buchler Instruments, Fort Lee, USA) at a flow rate of $0.5 \mathrm{ml} \mathrm{min}{ }^{-1}$ with fractions collected at intervals of $2 \mathrm{~min}$ into polystyrene vials using either a 2112 Redirac (LKB, Bromma, Sweden) or a 2110 Bio-Rad (Richmond, USA) fraction collector. Vials were maintained in iced water during the collection period.

The perifusion system was primed with warm choline chloride $\left(145 \mathrm{mmol} \mathrm{I}^{-1}\right)$ before introduction of the neurosecretosome suspension to the chambers. Each chamber was charged with $100 \mu \mathrm{l}$ of the suspension through a threeway stopcock that attached the afferent tubing to the chamber. Perifusion experiments were run for $4-5 \mathrm{~h}$ and included the following: an initial acclimatization period of between $30-60 \mathrm{~min}$ to allow the system to stabilize during which it was perifused with choline chloride solution. Perifusion with test solutions for periods of 20-30 min each was accomplished by switching from a reservoir of control solution to one containing the treatment solution. Each test period was followed by a further period of perifusion with choline chloride solution (see Fig. 1). Fractions were collected and stored at $-20^{\circ} \mathrm{C}$ until assayed. The perifusion system and solutions were maintained in an incubator at $37^{\circ} \mathrm{C}$ for the duration of the experiment. Neurosecretosomes were perifused with either choline chloride $(145 \mathrm{mmol}$ $\left.1^{-1}\right)$ as a control solution, or potassium chloride $\left(125 \mathrm{mmol}^{-1}\right)$ as an effective depolarizing medium with or without porcine relaxin $\left(25-100 \mathrm{nmol}^{-1}\right)$

Electron microscope examination. Samples of neurosecretosome pellets were prepared for electron microscopy. Pellets were fixed for $4-6 \mathrm{~h}$ with $2.5 \%$ glutaraldehyde, $2 \%$ paraformaldehyde in $0.2 \mathrm{~mol} \mathrm{HCl} 1^{-1}$ cacodylate buffer, $\mathrm{pH} 7 \cdot 4$, and then washed three times with $0.1 \mathrm{~mol}$ cacodylate buffer $\mathrm{l}^{-1}$ before post fixing in osmium tetroxide $(1.5 \%)$ for $90 \mathrm{~min}$. Before dehydration in an ascending series of ethanol concentrations $(30,50,70,95,100 \%)$, the pellets were again washed three times with cacodylate buffer. Pellets were then embedded in Jembed 812 resin (J.B. EM Services Inc., Dorval, Canada). Ultrathin sections were cut, stained with uranyl acetate and lead citrate and examined with a JOEL-100s microscope at $80 \mathrm{kv}$.

Electrical stimulation of the neural lobe. Post-pubertal gilts between days 14 and 21 of the oestrous cycle (courtesy of R. M. Liptrap, Department of Biomedical Sciences, University of Guelph) were anaesthetized with barbiturate ( $2.5 \mathrm{~g}$ in ethylene glycol), decapitated and the pituitary gland complex removed rapidly from the skull. The neural 
lobe, which had the pars intermedia and pars tuberalis attached, was dissected free from the anterior lobe. The former was then impaled on a silver wire stimulating electrode and immersed in normal Lockes' solution (NLS). After soaking the lobe for $40 \mathrm{~min}$ it was suspended in $0.5 \mathrm{ml}$ of fresh NLS and electrically stimulated as previously described (O'Byrne et al., 1986) with slight modifications as shown below. Five stimulations were conducted on each neural lobe from five sows. Each episode consisted of 1400 pulses, in seven envelopes of 200 pulses, delivered at a frequency of $20 \mathrm{~Hz}$ for $10 \mathrm{~s}$ once every $20 \mathrm{~s}$ using a $0.5 \mathrm{~mA}$ biphasic pulse of $1 \mathrm{~ms}$ duration. Porcine relaxin $\left(10^{-7}\right.$ mol $\left.1^{-1}\right)$ was added to the bathing solution during the second and fourth periods of stimulation in two of the five neural lobes studied. Samples of incubation media were frozen and assayed subsequently for oxytocin and porcine relaxin content.

\section{In vivo studies}

Animals. The effect of porcine relaxin on oxytocin release was studied during a number of suckling episodes in nine Yorkshire-Landrace, lactating sows, 6-12 days post partum, at the University Swine Research Centre. Sows were maintained in farrowing crates with their piglets for the duration of the experiment and had free access to both food and water.

Each sow had an ear vein cannula inserted as described by Anderson \& Elsley (1969) and Elliot et al. (1980) with slight modifications as follows. Sows were restrained with a rope snare, the ear cleaned, disinfected and a 14 gauge needle $(3.75 \mathrm{~cm}$ in length) was inserted into a vein, without anaesthesia, through which was passed $35-45 \mathrm{~cm}$ of a $1 \mathrm{~m}$ length of a previously sterilized (Cold Spor, Metrex Research Corp., Parker, USA) medical grade vinyl tubing (i.d. $0.86 \mathrm{~mm}$ o.d. $1.27 \mathrm{~mm}$, Dural Plastics \& Engineering, Auburn, NSW, Australia). The needle was then withdrawn and the cannula was attached to the ear with KaMar glue (Steamboat Springs, USA). The exposed portions of the cannula were protected, and anchored to the ear and side of neck, with adhesive tape (Smith and Newport Inc., Lachine, Canada) secured at the edges with tag cement (Livestock tag cement, Ruscoe Co., Akron, USA). A blood sample was drawn immediately to confirm that the cannula was patent. The cannula had been rinsed and filled with sterile heparinized ( $100 \mathrm{iu} \mathrm{ml}{ }^{-1}$, heparin sodium USP; Allen and Hanburys, Toronto, Canada) saline solution $(0.9 \%$ sodium chloride; MTC Pharmaceuticals, Cambridge, Canada) before implantation. After removal of the needle the free end of the tubing was attached to a $90 \mathrm{~mm}$ extension of Tygon plastic tubing (i.d. $0.8 \mathrm{~mm}$ o.d. $2.4 \mathrm{~mm}$; Fischer Scientific Corp.) which was closed with a blunt, stoppered 20 gauge needle to which a three-way stopcock was attached during blood sampling episodes. This extension permitted blood sampling without disturbing the sow. When not in use, the cannula was filled with heparinized saline $\left(200 \mathrm{iu} \mathrm{ml}^{-1}\right)$ and the extension tubing was stored in a plastic bag secured to the back of the sow with adhesive tape. Cannulae were inserted on the day before the experiment. The entire procedure took about $30 \mathrm{~min}$. To avoid disturbing the lactating sows unduly we implanted only one catheter in each sow. Although this compromised the measurement of porcine relaxin in the plasma samples, because of the likelihood of contamination after the bolus injections, we considered that sufficient information was available in the literature (e.g. O'Day et al., 1989) to predict the likely plasma concentrations. Moreover, because of the serial sampling for oxytocin the catheters were repeatedly flushed enabling us to confirm that porcine relaxin had been largely cleared by the third day of the experiment.

Blood sampling. Serial blood sampling commmenced the day after cannulae were implanted. Each sow was observed to suckle once before commencing the experiment to estimate the time of the next episode. Samples (6$10 \mathrm{ml}$ ) were then drawn into heparinized culture tubes at the following times: (1) approximately 5,10 and $15 \mathrm{~min}$ before the onset of suckling (estimated from the pre-experiment observation), (2) every $60 \mathrm{~s}$ for 5 min during milk ejection (sow presented her teats to litter coincident with rapid rhythmic grunting), (3) and at 10,15 and 20 min following the onset of milk ejection. Sows were observed to suckle, on average, every 45-60 min during the day and each nursing episode lasted approximately $5 \mathrm{~min}$. Sows were bled during two consecutive sucklings in the morning of each of three successive days.

Hormone treatment. Sows were injected with $10 \mathrm{ml}$ saline $(0.9 \%$ sodium chloride) within $5-10 \mathrm{~min}$ of the expected onset of the first experimental suckling on day I and day 3 of the experiment. On day 2, sows were injected, in a similar manner to that used on days 1 and 3 , but with a $1.5 \mathrm{mg}$ bolus of purified porcine relaxin dissolved in $1 \mathrm{ml}$ saline which was flushed through the cannula with $10 \mathrm{ml}$ saline. One sow (no. 41 ) was given a $3 \mathrm{mg}$ bolus of porcine relaxin. The doses of relaxin chosen were those calculated to give concentrations of $60-120 \mathrm{ng} \mathrm{ml}^{-1}$ in peripheral blood which is equivalent to the peak values expected in the periparturient sow (Sherwood et al., 1975, 1981; Sherwood, 1981).

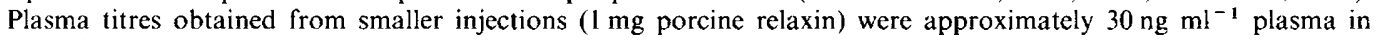
parturient sows (O'Day et al., 1989) which would be heavier than the sows used in this study.

Assessment of piglets. Piglets were weighed, to estimate milk consumption, on the day before the experiment commenced and before and after each nursing episode on each successive day. Litter size was not standardized and ranged from 7-11 piglets per sow. Foster piglets had been added to the litters of some sows as part of herd management.

Hormone assays. Previously validated radioimmunoassay methods were used to determine the content of oxytocin and porcine relaxin in plasma, and in perifusion and incubation solutions.

Relaxin radioimmunoassay. The details of the assay for porcine relaxin have been published elsewhere (Taverne et al., 1982). The antiserum (JJAB5, 1:6000 dilution) raised in rabbits by us, crossreacted $100 \%$ with CMa' relaxin 
(18-28 AAE-CMa' kindly donated by B. G. Steinetz), $<0.02 \%$ with porcine prolactin and $<0.01 \%$ porcine insulin (Sigma Chemicals, St Louis, USA). Sensitivity of the assay was between 3.5 and $33 \mathrm{pg}$ per tube (mean $=11.7 \mathrm{pg}$ per tube) and the intra- and interassay variations were $11 \%$ and $18 \%$, respectively $(n>10)$.

Oxytocin radioimmunoassay. Plasma was extracted for determination of oxytocin concentration using a modified version of the method of Wathes et al. (1986). The modifications are as follows, plasma (2-5 ml) was applied to a preconditioned Sep-Pak $\mathrm{C}_{18}$ cartridge (Waters Chromatography Division, Milford, USA) which was then washed with $15 \mathrm{ml}$ of $0 \cdot 1 \%$ trifluoracetic acid (TFA, Fisher Scientific Corp.) in water and the peptide eluted with $4 \mathrm{ml}$ of $80 \%$ acetonitrile (Certified ACS, Fischer Scientific Corp.). Plasma samples were passed through the cartridge a second time before washing and elution, and each cartridge was used twice. The mean extraction efficiency was $68 \cdot 2 \%$ (range $53-$ $89 \%$ ). Excess acetonitrile was blown off under a steady stream of air and the remaining aqueous phase was frozen at $-70^{\circ} \mathrm{C}$ and lyophilized overnight. Extracts were suspended in $1 \mathrm{ml}$ of $0.1 \mathrm{~mol}$ Tris buffer $1^{-1}$ with BSA and $50 \mu \mathrm{l}$ aliquots were taken, in triplicate, and assayed using a previously reported method (Wathes et al., 1983). Perfusate and incubation samples were assayed directly without extraction. The crossreactivity of the antiserum used $(85 / 2 \mathrm{~F}), 1$ : 11000 dilution (a gift from B. Pickering, University of Bristol, UK) with peptide hormones was as follows: mesotocin $(12.5 \%)$, lysine vasopressin $(0.03 \%)$ and other related peptides $(<0.001 \%)$. Sensitivity of the assay was between 5 and $30 \mathrm{pg}$ per tube (mean $=7.6 \mathrm{pg}$ per tube). The intra- and interassay coefficients of variation were $7.5 \%$ and $14 \cdot 1 \%$, respectively. The oxytocin standard (4th International Standard for oxytocin 76/575) used was obtained from the National Institute for Biological Standards and Control, London, UK (a WHO International Laboratory for Biological Standards).

\section{Results}

\section{In vitro studies}

Electron microscope examination of the neurosecretosome pellets showed that they contained a variety of cell fragments of which about $20 \%$ contained numbers of neurosecretory granules similar in size to those of rat neurosecretory granules (Morris, 1976), consisting of a central electron-dense material surrounded by a thin zone of lower electron density as described by Toescu \& Morris (1990).

Both perifusates and incubates of neurosecretosomes, as well as intact neural lobes, yielded measurable quantities of oxytocin $\left(0 \cdot 2-2 \cdot 0 \mu \mathrm{g} \mathrm{ml}^{-1}\right)$. As protein estimations of each neurosecretosome preparation were not made the results have been expressed in terms of percentage increase in oxytocin output compared with the pretreatment basal output. It was found that in the case of the neurosecretosome preparations the output of oxytocin fluctuated substantially about a mean that declined slowly but steadily with time. However, treatment with depolarizing concentrations of $\mathrm{KCl}$ consistently evoked a significant release in oxytocin from either the perifused (Fig. 1) or incubated neurosecretosomes. Similarly, initial electrical stimulation of the incubated intact neural lobe $(n=5)$ significantly enhanced the release of oxytocin from the gland $\left(150-1820 \mathrm{ng} \mathrm{m}^{-1}\right.$ above resting concentrations) which declined with subsequent stimulations. There appeared to be no correlation between oxytocin output from intact lobe preparations with the stage of the oestrous cycle of the sows.

In over fifty experiments, during a number of which conditions were modified in attempts to exclude possible artefacts that could account for the negative results, no significant change in oxytocin output from either neurosecretosomes or intact neural lobes occurred after exposure of the preparations to porcine relaxin in concentrations of $25-100 \mathrm{nmol}^{-1}$. The modifications included changing from the use of an infusion pump to a peristaltic system to provide for a more reliable transition between control and test solutions, the use of different types of filters to hold the preparations during perifusion and the adoption of incubations to avoid pressure artefacts inherent in perifusion systems. The negative findings were true also for the intact neural lobe irrespective of whether this was undergoing stimulated or basal oxytocin release.

\section{In vivo experiments}

All sows showed a normal pattern of suckling behaviour except during one bleeding episode each in sows no. 24 (not shown) and no. 41 (Fig. 3e) when suckling was unfortunately interrupted by an attendant and a normal plasma oxytocin spike could not be demonstrated. In each case the 

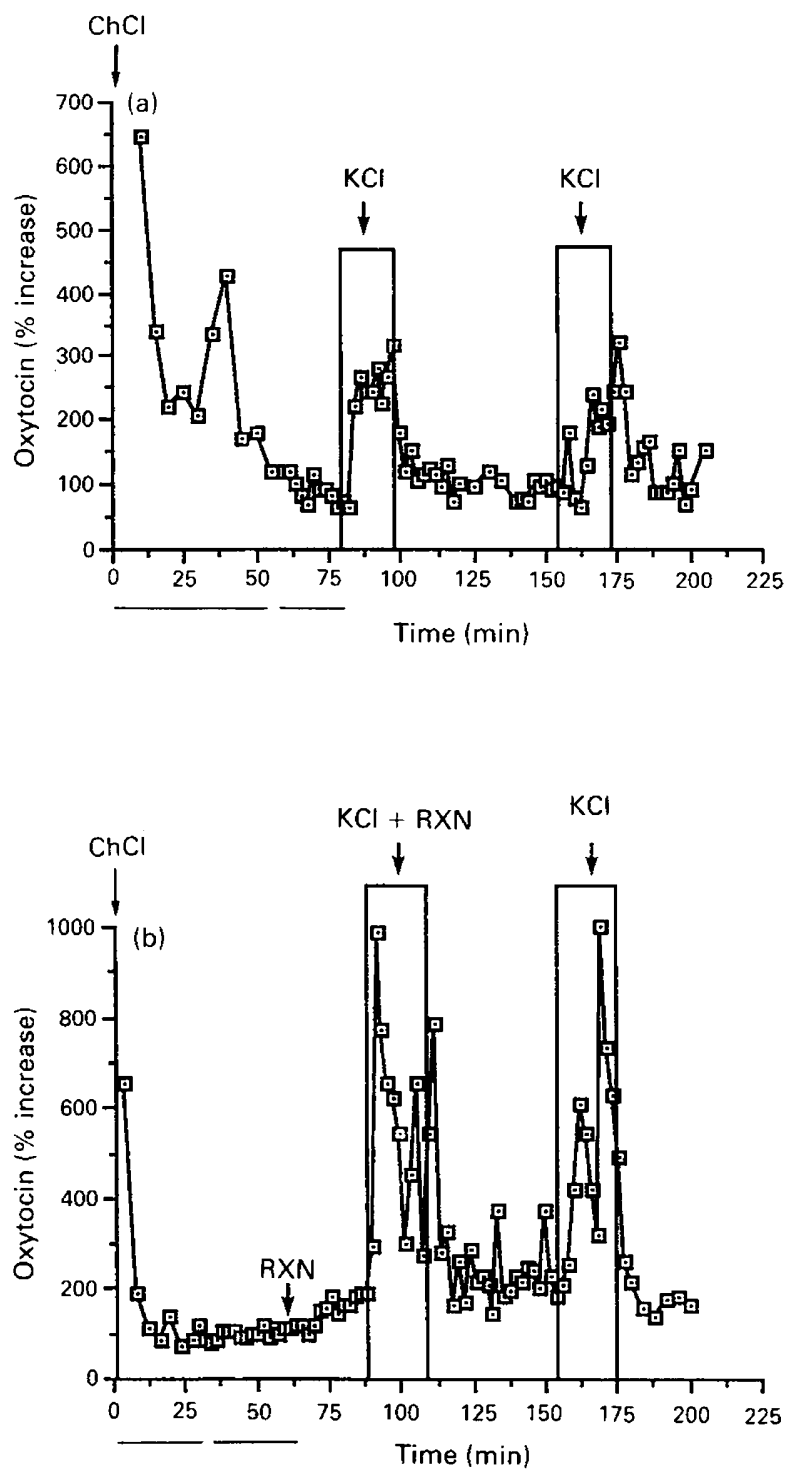

Fig. 1. Percentage increases in oxytocin concentration in media collected from perifused neurosecretosomes from two pig neurohypophyses. Samples were taken every 5 min initially (during acclimatization period indicated by first bar, $x$ axis) followed by every two minutes (arbitrary basal period indicated by second bar, $x$ axis). (a) Neurosecretosomes were perifused for $4 \mathrm{~h}$ with 145 mmol choline chloride $\mathrm{l}^{-1}(\mathrm{ChCl})$ or for short periods $125 \mathrm{mmol}$ potassium chloride $\mathrm{l}^{-1}$ ( $\mathrm{KCl}$ ) where indicated (arrows). (b) Porcine relaxin ( $\mathrm{RXN}$ ) was added to the perifusate and there was no significant effect upon either basal or potassium-stimulated oxytocin release. The results are expressed as percentage increases in oxytocin concentration compared to the mean concentration measured during the arbitrary basal period (indicated by second bar) that was taken following a period of acclimatization (indicated by first bar) during which irregular fluctuations in oxytocin output were common (see (a)).

sow would make her nipples available to the litter after initiating the suckling session by a series of grunts which alerted the piglets. The mean number of piglets suckled was $9 \pm 0.47$ per sow. All litters showed normal weight gain patterns throughout the course of the experiment (Table 1). 
Table 1. Mean litter size, mean litter weight $(\mathrm{kg})$ before and after each treatment period

\begin{tabular}{|c|c|c|c|c|c|c|c|c|}
\hline \multirow{3}{*}{$\begin{array}{l}\text { Number of } \\
\text { sows }\end{array}$} & \multirow{3}{*}{$\begin{array}{c}\text { Number of } \\
\text { piglets } \\
\text { per sow }\end{array}$} & \multicolumn{7}{|c|}{ Litter weight (kg) } \\
\hline & & \multirow[b]{2}{*}{ Day $0^{*}$} & \multicolumn{2}{|c|}{ Day 1 saline } & \multicolumn{2}{|c|}{ Day 2 relaxin } & \multicolumn{2}{|c|}{ Day 3 saline } \\
\hline & & & Before & After & Before & After & Before & After \\
\hline 9 & $9 \pm 0.47$ & $2 \cdot 77 \pm 0 \cdot 2$ & $98 \pm 0.2$ & $00 \pm 0$ & $22 \pm 0$ & $23 \pm c$ & $\cdot 44 \pm 0$ & $\cdot 47 \pm 0 \cdot 19$ \\
\hline
\end{tabular}

*Piglets were first weighed on the day the ear cannula was implanted.

Values are means \pm SEM.

After saline injection via the indwelling ear vein catheter the sows exhibited a spike in plasma oxytocin concentration of between 25 and $75 \mathrm{pg} \mathrm{ml}^{-1}$ coinciding with the onset of milk ejection to the piglets (Figs $2 \mathrm{a}, \mathrm{b}$ and $3 \mathrm{a}, \mathrm{b}$ ). The plasma titres fell rapidly after the peak to less than $10 \mathrm{pg} \mathrm{ml}^{-1}$ by $20 \mathrm{~min}$ after the onset of suckling.

On day 2, when the same sows were given injections of porcine relaxin of 1.5 or $3.0 \mathrm{mg}$ i.v., suckling behaviour was normal and spikes of oxytocin were measured in the plasma which were of comparable titres to those measured during the control experiments. This was so even with the $3 \mathrm{mg}$ dose of porcine relaxin which would have raised plasma porcine relaxin titres to approximately $120 \mathrm{ng} \mathrm{ml}^{-1}$ contemporaneously with the milk ejections.

No delayed effect of the porcine relaxin treatment was observed in the sows when saline injections were given and plasma oxytocin titres measured on day 3. Oxytocin spikes were comparable to those recorded on days 1 and 2 (Figs 2 and 3). Relaxin titres in all the sows on day 3 were below $0.5 \mathrm{ng} \mathrm{ml}^{-1}$, notwithstanding the possibility of some residual contamination from the cannula. Contamination or noise in the assay as values approached the limits of its sensitivity may have accounted for the apparently wide fluctuations of porcine relaxin values on day 3 .

We could not measure porcine relaxin in the samples taken from sows on day 1 at any time during the suckling periods.

\section{Discussion}

This study has failed to reveal any significant effect of treatment with homologous porcine relaxin on the output of oxytocin from the neural lobes of nonpregnant cycling sows in vitro or from lactating sows in vivo, even when neural lobe preparations were exposed in vitro to concentrations of porcine relaxin up to $10^{-7} \mathrm{~mol}^{-1}$ and administering up to $3.0 \mathrm{mg}$ of porcine relaxin to sows in vivo which was expected to raise plasma titres in vivo probably to as much as $120 \mathrm{ng} \mathrm{ml}^{-1}$. The study of neural tissue in vitro failed to demonstrate any effect of porcine relaxin on basal or stimulated output of oxytocin. The experiments using potassium depolarization could have applied a supramaximal stimulus $\left(125 \mathrm{mmol} \mathrm{K}^{+} \mathrm{l}^{-1}\right)$ which would have over-ridden any effect of porcine relaxin but they were similar to that $\left(100 \mathrm{mmol} \mathrm{K}^{+} \mathrm{l}^{-1}\right)$ used by Dayanithi et al. (1987). Morover, the lack of effect was consistent in the electrically stimulated intact lobe, but again that might have represented supramaximal stimulus. The lack of effect of porcine relaxin on oxytocin output was consistent with the failure of porcine relaxin treatment to alter suckling behaviour in any way or to affect weight gain adversely in the litters. The oxytocin spikes recorded during suckling episodes were consistent with those reported by Ellendorf et al. (1982) and Uvnas-Moberg et al. (1985) but were slightly higher than that reported by Okrasa et al. (1989) which may reflect differences in the frequency of blood sampling at the time of suckling.

Afele et al. (1979) reported that plasma relaxin concentrations increase on suckling in the sow and Whitely et al. (1985) claimed that the concentrations can be related to the level of suckling activity shown by the piglets. In the present study we could not detect any increase in porcine 
Suckling episode 1
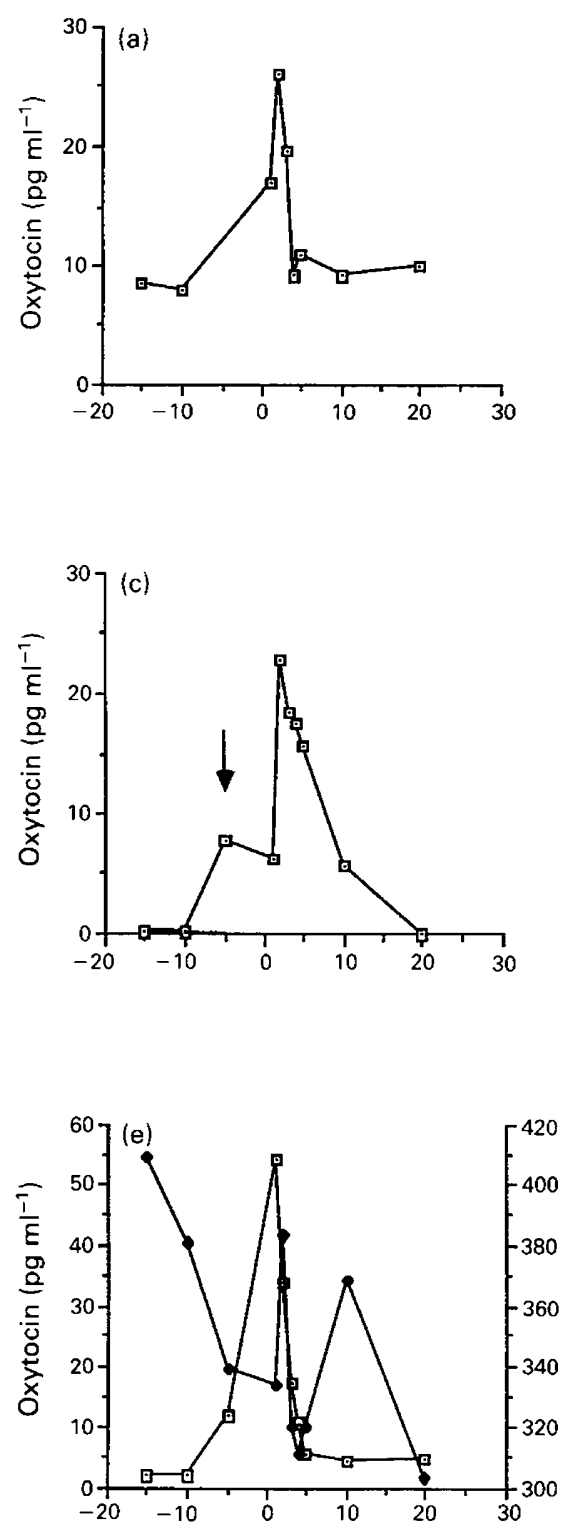

Suckling episode 2
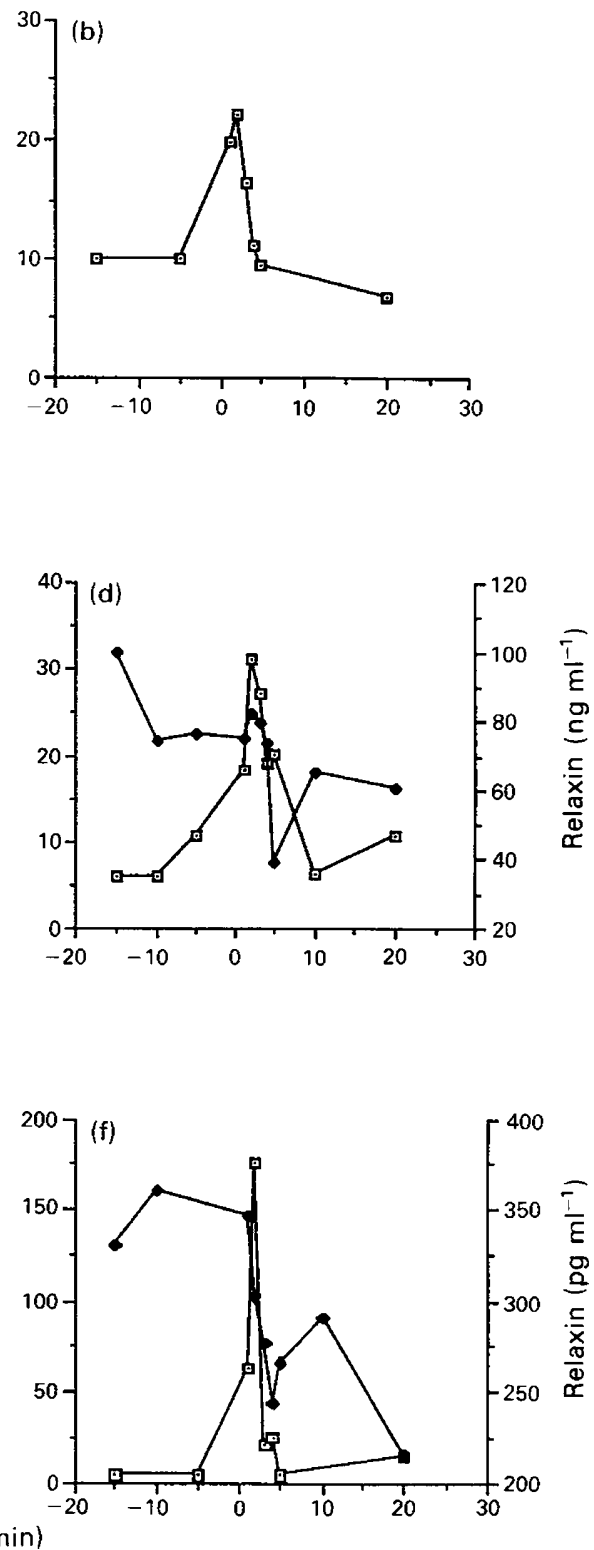

Fig. 2. Plasma (๑) oxytocin and $(\bullet)$ relaxin profiles of a representative sow (no. 23) bled during two consecutive sucklings (episode 1: (a), (c), (e); episode 2: (b), (d), (f)) on each of three successive days. Day 1 (a,b); day 2 (c) $1.5 \mathrm{mg}$ purified porcine relaxin injected as indicated (arrow), and (d) relaxin and oxytocin titres; day $3(\mathrm{e}, \mathrm{f})$.

relaxin titres in plasma collected coincident with suckling and the plasma oxytocin spike of reflex milk ejection (Ellendorf et al., 1982). When porcine relaxin was detected the concentrations were low $\left(<120 \mathrm{pg} \mathrm{ml}^{-1}\right)$ and in most cases below the sensitivity of the assay which contrasts with the peak plasma relaxin values (4-16 $\mathrm{ng} \mathrm{ml}^{-1}$ ) reported by Afele et al. (1979) and Whitely et al. (1985). Our results are consistent with those of two other laboratories (Sherwood et al., 1981 and Kendall et al., 1983) that also failed to detect any increase in relaxin titres during suckling episodes. It is 

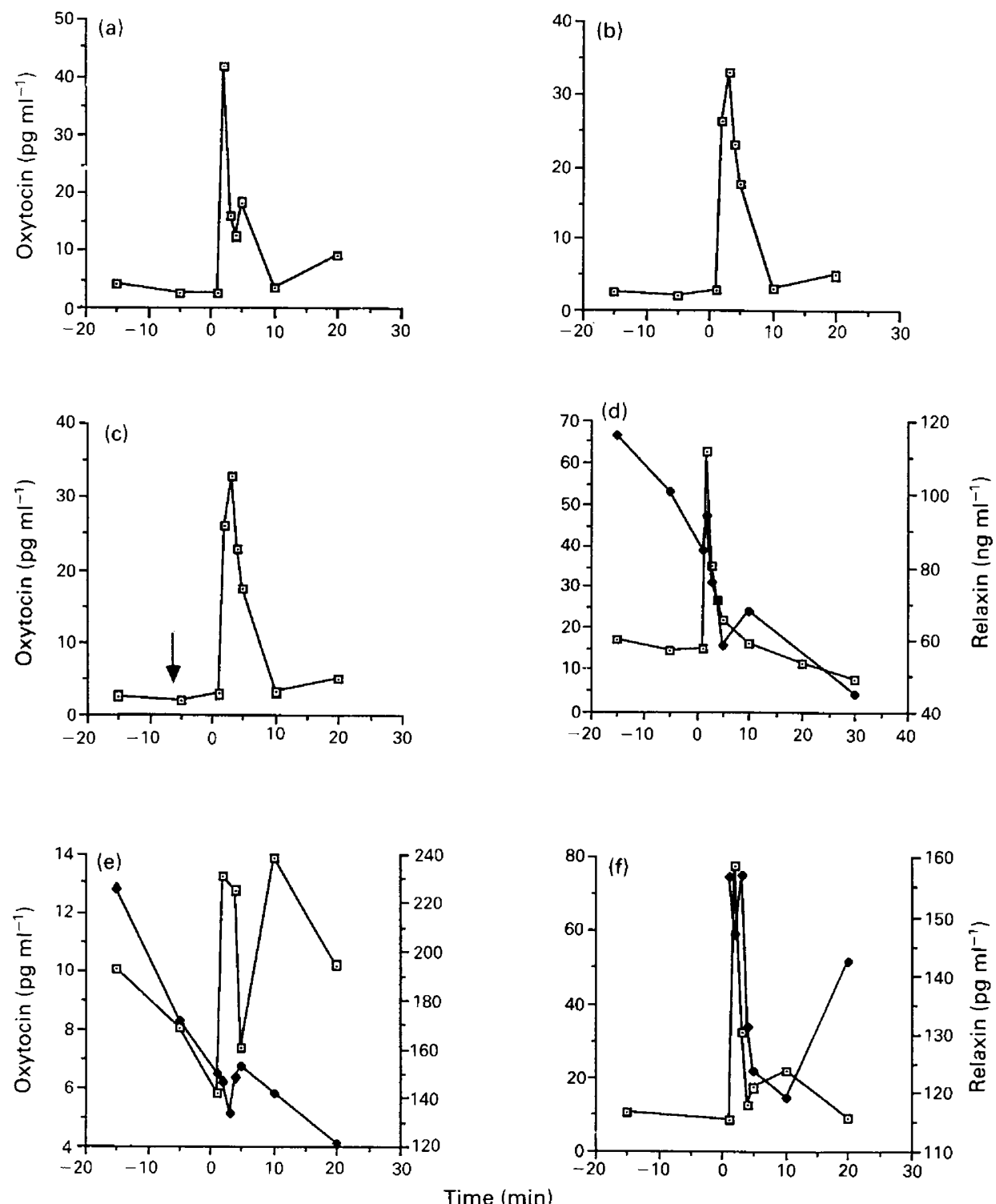

Fig. 3. Plasma $(\square)$ oxytocin and $(\bullet)$ relaxin profiles of a representative sow (no. 41) bled during two consecutive sucklings (episode 1: (a), (c), (e); episode 2 (b), (d), (f)) on each of three successive days. Day $1(\mathrm{a}, \mathrm{b})$; day $2(\mathrm{c}), 3.0 \mathrm{mg}$ purified porcine relaxin injected as indicated (arrow), and oxytocin and relaxin titres (d); day $3(\mathrm{e}, \mathrm{f})$.

difficult to explain the differences between these studies especially as there is a problem in accounting for the rapid falls in relaxin concentrations that followed the peaks reported by Afele et al. (1979) and Whitely et al. (1985) given our knowledge of clearance rates for relaxin (Sherwood \& Downing, 1983). It is possible, however, that if the source of relaxin was the neural lobe of the hypothalamus, as recent work seems to suggest (see below), small pulses of relaxin might be detected depending upon the position of the sampling catheter in relation to the jugular vein. We conclude, however, that at present evidence points away from the likelihood that sows secrete relaxin during suckling and reflex milk ejection. 
These results are in sharp contrast to our findings in the rat (Summerlee et al., 1984) where injections of porcine relaxin into the anaesthetized suckling rat interrupted milk ejections in a dosedependent manner. The reason for this difference is unknown. Recently, there have been claims that relaxin can be identified immunohistochemically in the neurohypophysis of pigs (Bagnell, 1990). We have been able to detect porcine relaxin in effluent from stimulated porcine neural lobes in vitro (Ryan et al., 1991) which is consistent with such a finding. The physiological significance of these observations is unclear and whether an ability of the neural lobe of the hypothalamus to secrete relaxin might render it unresponsive to circulating relaxin can be answered only by further studies.

The explanation for the finding (Wathes et al., 1989) that the duration of farrowing is positively related to the post-spike plasma porcine relaxin concentrations would thus seem to lie in mechanisms other than an inhibition of oxytocin secretion. Relaxin inhibits myometrial contractions in sows (Watts et al., 1988) and high titres in the immediate pre-farrowing period might be sufficient to slow the progress of delivery. This would differ from the rat because, although continuous infusions of porcine relaxin prolonged pregnancy in rats, deliveries that occurred after infusions were stopped were accomplished significantly faster than normal (Jones \& Summerlee, 1986b).

From the results of our study we suggest that circulating relaxin does not affect oxytocin release in sows and that the hormone could be used at farrowing without deleterious effects on suckling. However, we do not know for certain whether the neural lobe of the parturient sow behaves differently from that of the lactating and cyclic animal.

We thank $\mathrm{C}$. Wasnidge (porcine relaxin radioimmunoassays), $\mathrm{K}$. Minhas (EM preparation), M. Loster and S. Hulland (in vivo study) for excellent technical assistance, R. M. Liptrap for providing the porcine pituitaries, A. J. S. Summerlee for assistance with the electrophysiology and S. Birkett (University of Bristol) for advice on the oxytocin assay. This study was supported by grants from the Natural Science and Engineering Council (Canada) no. OGP 0036, Ontario Pork Industry Improvement Plan and the University of Guelph Research Excellence Fund. Part of this work was presented at the 24th annual meeting of the Society for the Study of Reproduction, July 29-31, 1991, University of British Columbia, Vancouver, Canada (Ryan et al., 1991).

\section{References}

Afele, S., Bryant-Greenwood, G.D., Chamley, W.A. \& Dax, E.M. (1979) Plasma relaxin immunoactivity in the pig at parturition and during nuzzling and suckling. Journal of Reproduction and Fertility 56, $451-457$.

Anderson, D.M. \& Elsley, F.W.H. (1969) A note on the use of indwelling catheters in conscious adult pigs. Journal of Agricultural Science 72, 475-477.

Bagnell, C.A. (1990) Identification of immunoreactive relaxin in the neurophypophysis of the pig. Biology of Reproduction 42 (Supplement 1) 102, (Abstract).

Cazalis, M., Dayanithi, G. \& Nordmann, J.J. (1987) Hormone release from isolated nerve endings of the rat neurohypophysis. Journal of Physiology 390, $55-70$.

Dayanithi, G., Cazalis, M. \& Nordmann, J.J. (1987) Relaxin affects the release of oxytocin and vasopressin from the neurohypophysis. Nature 325, $813-816$.

Downing, S.J., Bradshaw, J.M.C. \& Porter, D.G. (1980) Relaxin improves the coordination of rat myometrial activity in vivo. Biology of Reproduction 23, 899-903.

Ellendorf, F., Forsling, M.L. \& Poulain, D.A. (1982) The milk ejection reflex in the pig. Journal of Physiology $333,577-594$.
Elliot, J.I., King, G.J. \& Robertson, H.A. (1980) Reproductive performance of the sow subsequent to weaning piglets at birth. Canadian Journal of Animal Science 60, 65-71.

Jones, S.A. \& Summerlee, A.J.S. (1986a) Relaxin acts centrally to inhibit oxytocin release during parturition: an effect that is reversed by naloxone. Journal of Endocrinology 111, 99-102.

Jones, S.A. \& Summerlee, A.J.S. (1986b) Effects of porcine relaxin on the length of gestation and duration of parturition in the rat. Journat of Endocrinology 109, 85-88.

Kendall, J.Z., Richards, G.E. \& Shih, L.N. (1983) Effect of haloperidol, suckling, oxytocin and hand milking on plasma relaxin and prolactin concentrations in cyclic and lactating pigs. Journal of Reproduction and Fertility 69, 271-277.

Morris, J.F. (1976) Hormone storage in individual neurosecretory granules of the pituitary gland: a quantitative ultrastructural approach to hormone storage in the neural lobe. Journal of Endocrinology 68, 209-223.

Musah, A.I., Schawbe, C. \& Anderson, L.L. (1989) Relaxin regulates oxytocin secretion in late pregnant beef heifers. Proceedings of Society for Experimental Biology and Medicine 191, 124-129. 
Nara, B.S., Welk, F.A., Rutherford, J.E. \& Sherwood, O.D. (1982) Effect of relaxin on parturition and frequency of live births in pigs. Journal of Reproduction and Fertility 66, 359-365.

O'Byrne, K.T., Eltringham, L., Clarke, G. \& Summerlee, A.J.S. (1986) Effects of porcine relaxin on oxytocin release from the neurohypophysis in the anaesthetized lactating rat. Journal of Endocrinology 109, 393-297.

O’Day, M.B., Winn, R.J., Easter, R.A., Dzuik, P.J. \& Sherwood, O.D. (1989) Hormonal control of the cervix in pregnant gilts. II. Relaxin promotes changes in the physical properties of the cervix in ovariectomized hormone-treated pregnant gilts. Endocrinology 125, 3004-3010.

Okrasa, S., Kotwica, G., Ciereszko, R., Dusza, L. \& Czarnyszewicz, J. (1989) Hormonal changes during lactation in sows: influence of spontaneous suckling on prolactin, oxytocin and corticoid concentrations. Experimental and Clinical Endocrinology 93, 95-103.

Ryan, R.L., Norman, L. \& Porter, D.G. (1991) Relaxin does not affect oxytocin from the porcine neural lobe in vitro or in lactating sows in vivo. Biology of Reproduction 44, Supplement 1, 105 (Abstract).

Sherwood, O.D. (1981) Relaxin at parturition in the pig. In Control of Pig Reproduction, pp. 343-376. Eds D.J.A. Cole \& G.R. Foxcroft. Butterworths, London.

Sherwood, O.D. \& Downing, S.J. (1983) The chemistry and physiology of relaxin. In Factors Regulating Ovarian Function, pp. 381 410. Eds G. S. Greenwald and P. Terranova, Raven Press, New York.

Sherwood, O.D., Chang, C.C., BeVier, G.W. \& Dziuk, P.J. (1975) Radioimmunoassay of plasma relaxin levels throughout pregnancy and at parturition in the pig. Endocrinology 97, 834-837.

Sherwood, O.D., Nara, B.S., Welk, F.A., First, N.L. \& Rutherford, J.E. (1981) Relaxin levels in the maternal plasma of pigs before, during, and after parturition and before, during, and after suckling. Biology of Reproduction 25, 65-71.

Summerlee, A.J.S., O'Byrne, K.T., Paisley, A.C., Breeze, M.F. \& Porter, D.G. (1984) Relaxin affects the central control of oxytocin release. Nature 309, 372-374.

Taverne, M., Bevers, M., Bradshaw, J.M.C., Dieleman, S.J., Willemse, A.H. \& Porter, D.G. (1982) Plasma concentrations of prolactin, oestadiol-17 $\beta$ in sows treated with progesterone, bromocriptine or indomethacin during late pregnancy. Journal of Reproduction and Fertility 65, 85-96.

Toescu, E.C. \& Morris, J.F. (1990) Morphometric analysis of nerve endings isolated from bovine and rat neurohypophysis. Journal of Anatomy 173, 1-17.

Uvnas-Moberg, K., Stock, S., Eriksson, M., Linden, A., Einarsson, S. \& Kunavongkrit, A. (1985) Plasma levels of oxytocin increase in response to suckling and feeding in dogs and sows. Acta Physiologica Scandinavica 124, 391-398.

Wathes, D.C., Swann, R.W., Birkett, S.D., Porter, D.G. \& Pickering, B.T. (1983) Characterization of oxytocin, vasopressin and neurophysin from the bovine corpus luteum. Endocrinology 113, 693--698.

Wathes, D.C., Guldenaar, S.E.F., Swann, R.W., Webb, R., Porter, D.G. \& Pickering, B.T. (1986) A combined radioimmunoassay and immunocytochemical study of ovarian oxytocin production during the periovulatory period in the ewe. Journal of Reproduction and Fertility $78,167-183$.

Wathes, D.C., King, G.J., Porter, D.G. \& Wathes, C.M. (1989) Relationship between pre-partum relaxin concentrations and farrowing intervals in the pig. Journal of Reproduction and Fertility 87, 383-390.

Watts, A.D., Flint, A.P.F., Foxcroft, G.R. \& Porter, D.G. (1988) Plasma steroid, relaxin and dihydro-ketoprostaglandin $F-2 \alpha$ changes in the minipig in relation to myometrial electrical and mechanical activity in the pre-partum period. Journal of Reproduction and Fertility 83, 553-564.

Whitley, J., Willcox, D.L., Hartmann, P.E, Yamamoto, S.Y. \& Bryant-Greenwood, G.D. (1985) Plasma relaxin levels during suckling and oxytocin stimulation in the lactating sow. Biology of Reproduction $33,705-714$.

Received 14 August 1991 